\title{
A Combined Methodology for Landslide Risk Mitigation in Basilicata Region by Using LIDAR Technique and Rockfall Simulation
}

\author{
G. Colangelo ${ }^{1}$ and A. Guariglia ${ }^{2}$ \\ ${ }^{1}$ Department of Infrastructure and Civil Protection, C.so Garibaldi 139, 85100 Potenza, Italy \\ ${ }^{2}$ GEOCART, Engineering Company, Viale del Basento 120, 85100 Potenza, Italy
}

Correspondence should be addressed to G. Colangelo, gerardo.colangelo@regione.basilicata.it

Received 30 March 2011; Accepted 18 May 2011

Academic Editor: Francesco Soldovieri

Copyright ( $) 2011$ G. Colangelo and A. Guariglia. This is an open access article distributed under the Creative Commons Attribution License, which permits unrestricted use, distribution, and reproduction in any medium, provided the original work is properly cited.

\begin{abstract}
Rockfalls represent a significant geohazards along the SS18 road of Basilicata Region, Italy. The management of these rockfall hazards and the mitigation of the risk require innovative approaches and technologies. This paper discusses a hazard assessment strategy and risk mitigation for rockfalls in a section of SS118, along the coast of Maratea, using LIDAR technique and spatial modelling. Historical rockfall records were used to calibrate the physical characteristics of the rockfall processes. The results of the simulations were used to define the intervention actions and engineering strategy for the mitigation of the phenomena. Within two months, 260 linear meters of high-energy rockfall barriers for impact energies up to $3000 \mathrm{~kJ}$ were installed. After that, according to road authority, the SS18 road was opened in a safe condition. The results represent a valid cognitive support to choose the most appropriate technical solution for topography strengthening and an example of good practice for the cooperation between innovative technologies and field emergency management.
\end{abstract}

\section{Introduction}

The geology, relief, neotectonics, climate, and vegetation of Basilicata make the region vulnerable to landslides, but the number of reported landslides in the region has increased over recent centuries, and this has been interpreted as a result of changes in land use [1]. The main typologies of landslide in Basilicata Region are represented principally by earth flow, rock fall and complex landslide due to the combination of movement. The landslide phenomena involved buildings and infrastructures constructed on the slopes. The risk for people and assets needed the intervention of the endusers involved in the risk management and, in particular, the inspection of Regional Department of Infrastructure and Civil Protection (RDICP). In many involved areas (roads, buildings, etc.) and for many families evacuation decrees have been issued in order to allow the damage valuation. The complexity of the phenomena demanded a multidisciplinary approach based on the integration of all the data (direct and indirect) acquired in the affected areas. An important contribution to obtain high-resolution information on the geomorphology can be provided by LiDAR thecnique (light detection and ranging). The LiDAR is an active high-resolution technology capable to provide accurate three-dimensional topography measurements. Many examples of the LiDAR application are reported in the literature $[2,3]$. In many cases the results of its application allowed to reconstruct the geometry of the slope, to locate the source area of rockfall, and so forth. By using airborne full-waveform laser scanning, some LiDAR have been performed in some damaged areas of the Basilicata region.

In this paper we present the results of Rasi rockfall landslide, located at the western side of Maratea town. Airborne LiDAR data acquisition was carried out on February 2010 for Rasi and surrounding areas. The LiDAR technique allowed us to obtain DTM with a high resolution of $0.25 \mathrm{~m}$. The area have been preliminary studied and rockfall source area have been individuated by the technical staff of the RDICP. 
At the same time, the information coming from the airborne LiDAR have been very useful in the phases of the valuation damage and to design engineering solution [4].

\section{Geological Setting}

The investigated areas are located in Basilicata Region, along the west zone of southern Apennines chain. The latter is mainly composed of sedimentary cover of platform and deep water environments, scraped off from the former Mesozoic Ligurian ocean, from the western passive margin of the Adriatic plate and from the Neogene-Pleistocene foredeep deposits of the active margin. From west to east, the main Mesozoic domains are as follows: (1) the internal oceanic to transitional Liguride-Sicilide basinal domains (internal nappes), (2) the Apennine carbonate platform, (3) the Lagonegro-Molise basins, and (4) the Apulian carbonate platform [5].

Maratea area is characterized by carbonate rocks outcrop. They belong to the Bulgheria-Verbicaro and AlburnoCervati Units and exhibit heavy fracturing and occasional karstification. The structural setting depends on the overthrusting of carbonate rocks of the Bulgheria-Verbicaro Unit on the clayey-marly made of the plastic soils of the Liguride Unit [6].

On February 2010 a rockfall event occurred to Maratea town in the Rasi area. The rockfall was caused by the high state of fracturing of the outcrops dolomite limestone rocks. After an impact on the material poured out on the debris, the blocks have determined a real discharge of debris on the SS18 road (Figure 1).

The debris on the slope was characterized by elements of different size $\left(0.5-1 \mathrm{~m}^{3}\right)$. A part of the debris has stopped its course on SS18 road while another part of debris with highest volume has continued its race for rolling up to the next portion and the lower wooded slopes until sea.

Historical rockfall records were used to calibrate the physical characteristics of the rockfall processes [7]. In the study area was carried out a field measurements to define the geomechanical properties of rock outcrops [8].

\section{LIDAR Technique and Modelling}

After the closing of the SS18 by ANAS road authority, for the complexity of the phenomena and for the changing of the morphology of the slope, the RDICP needed to have detailed information to evaluate appropriate strategy. To this aim a high-resolution scanning airborne topographic LiDAR was deployed.

3.1. Survey System. The system is characterized by a Flight Management System-CCNS (computer-controlled navigation system), by a Riegl LMS-Q560 high-resolution laser measurement system, by a sensor system control and data logging unit (LMcontrol), DigiCAM-medium-format airborne digital camera system.

A peculiar characteristic of Riegl LMS-Q560 is the "Full Waveform" recording that guarantees a vertical resolution less than $50 \mathrm{~cm}$ if compared to noncontinuous lasers

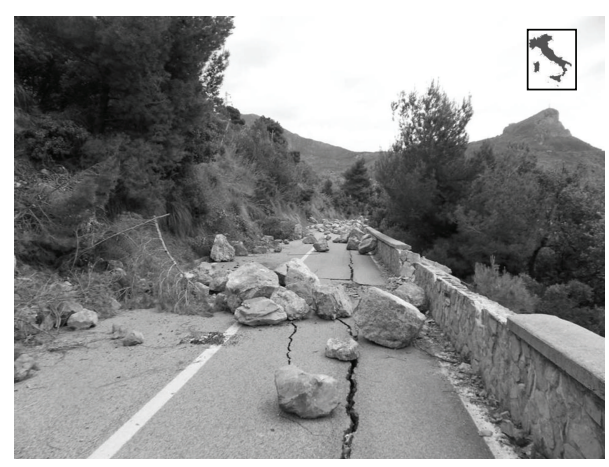

FIGURE 1: Rockfall on SS18 road located in the Rasi area.

(4 echoes) characterized by a vertical resolution higher than $1.20 \mathrm{~cm}$. The flight plan is characterized by flight level of $500 \mathrm{~m}$, speed 50 knots, and pulse repetition rate $240 \mathrm{KHz}$ and 45 flight lines with side overlap of $60 \%$. Double refinement with crossed lines and side overlap of $80 \%$ has been measured. The point density is $25 \mathrm{pt} / \mathrm{sqm}$ on the whole area and $200 \mathrm{pt} / \mathrm{sqm}$ on area affected by landslides, the photo with ground sample has a distance $<10 \mathrm{~cm}$.

3.2. Laser Data Processing. The laser data have to be processed to produce a cloud of points preclassified.

For each pulse the system records the full waveform that have to be analyzed to obtain the echoes. Afterward each echo has to be georeferenced through the GPS-INS information.

The Full waveform was processed or decomposed into a sum of components or echoes (that can be unlimited) where each component represents the target shoot. The amplitude of each component is recorded as intensity with a dynamic range of 16 bits ( 65.536 colors). In addition, the Echo digitization with subsequent full-waveform analysis provides much more information on the target characteristics compared to conventional laser ranging systems. For each echo are associated the range, the echo width, and the amplitude.

3.3. Rockfall Modeling. Rockfalls 2D-3D numerical simulations were carried out using two different methods in order to forecast the velocities, the bounce heights, and the possible impact energy on the dynamic barriers.

In particular, due to computational cost of $3 \mathrm{D}$ simulations, they have been used only to define the main trajectories of the rockfall. To refine the results obtained by the previous simulations, a 2D model has been introduced.

The 3D model used for the computation of the trajectories of rockfalls considers the blocks like point block that have an impact on an elevation attributed plane. This plane is formed by a grid of tridimensional nodes that form a triangular mesh which represents the entire area between the launch and the stopping of the blocks.

The elements of the grid have been defined so that, in the inside of the perimeter, the inclination and the direction of the slope together with the physical parameters of the model (Table 1), defined as ratio of the post- and pre-impact energy, can be considered constants. 
TABLE 1: Physical parameters used in the model.

\begin{tabular}{lccc}
\hline Material & \multicolumn{2}{c}{ Coefficients } & Friction angle \\
& $R n$ & $R t$ & $\theta$ \\
\hline Bedrock outcrops & $0.35 \pm 0.04$ & $0.85 \pm 0.04$ & $28 \pm 2$ \\
Talus cover & $0.40 \pm 0.04$ & $0.80 \pm 0.04$ & $28 \pm 2$ \\
Talus with & $0.32 \pm 0.04$ & $0.45 \pm 0.04$ & $28 \pm 2$ \\
vegetation & $0.40 \pm 0.04$ & $0.90 \pm 0.04$ & $30 \pm 2$ \\
Asphalt & & &
\end{tabular}

The definition of the launch area assumes a previously analysis of the launch niche so that for every block a launch velocity as a function of the initial route along the wall can be defined.

This model also carries out the analysis for the positioning and sizing of protective works. The initial computation verifies that the block knocks against the barrier and does not climb over it, so it verifies that the impact kinetic energy of the block can be completely absorbed by the protective work.

This model for the computation of trajectories of rock falls is mostly used for the design of embankments as protective works because, thanks to their high expansion, the embankments can be able to intercept a great number of blocks before requiring maintenance interventions or reconstruction, and assure a remarkable absorption energy, typically generated by long fall routes.

The trajectory of the block can be determined by using the motion equations of a block. Referred to as cartesian orthogonal axis system these equations are as follows:

$$
\begin{gathered}
s=v \cdot t+s_{0}, \\
z=-\frac{1}{2} \cdot g \cdot t^{2}+v z \cdot t+z_{0},
\end{gathered}
$$

where $v=$ block velocity; $t=$ time; $g=$ gravitational constant; $s=$ crossed space.

In this way the trajectory of the motion results to be formed by a series of parabolas drawn from the launch point to the impact points on the slope, in the initial phase of the motion, and between two consecutive impact points on the slope, or at the foot, until the stopping point.

By indicating with $v n$ and $v t$ the components (normal and tangential) of the velocity before the impact, $v^{\prime} n$ and $v^{\prime} t$ after the impact can be calculated using the following relations:

$$
\begin{aligned}
v^{\prime} n & =v n \cdot \ln , \\
v^{\prime} t & =v t \cdot \mathrm{lt},
\end{aligned}
$$

where $\ln$ and lt are the restitution coefficients, varying in the interval 0-1 [9].

About 2D simulations, a lumped-mass method used to design safe slopes. Based on a statistical analysis of fall paths in 2D, it calculates trajectories and rebound energy for falling blocks as well as velocity and height for any point of a slope. It also estimates the location of the fall-path endpoint, which is the most significant factor affecting safety.

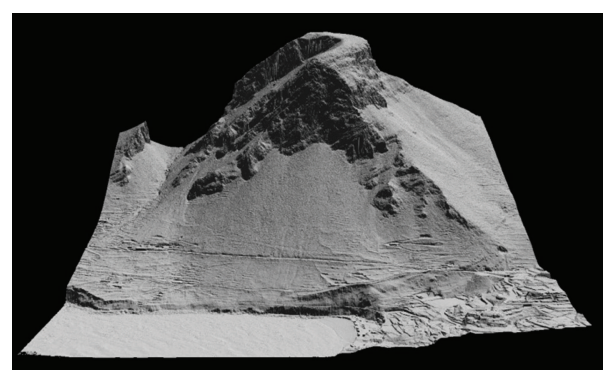

FIGURE 2: High-resolution DTM obtained by airborne full-waveform laser scanning.

In this code every rock is modelled as an infinitely small particle. Rock size is thus not considered, but the equations used in the sliding algorithm reflect shapes that are circular.

Since each rock is infinitely small there is no interaction between particles, only with segments of slope, so each rock behaves as if participating alone in the simulation.

This means that noncleaned catch benches are not well reflected in the code unless the debris slope is explicitly modelled as part of the slope.

RocFall 4.0 is a more or less raw model of the mechanical process of a rockfall, as it does not take into account block shape, size, or angular momentum. Nevertheless, it has the important advantages that its calculations include statistical distributions of the parameters and that it operates very rapidly. In a mining exploitation it is impossible to know falling block shape and size in advance; nonetheless, this code is appropriate for the purpose of modelling rockfall in quarries, given that it is not that difficult to assume statistical distributions for restitution coefficients and friction angles [10].

\section{Analysis of the Results}

The information associated with the geological, geomorphological, and impact sighs along the slope allowed us to define the geomechanic parameters used for the modelling.

During the first part of the emergency the removal of instable blocks on the slope permitted us to have information to support for the back analysis. In fact during these operations, it was possible to following the real trajectory of the blocks and the bounce height envelope. At the same time, a DTM with $0.25 \mathrm{~m}$ of accuracy was produced on the area along SS18 road close to the Maratea coast (Figure 2).

The DTM associated with the simulations had a dual use, both during the emergency and in the phase of design engineering solution.

In particular, during the emergency, dangerous areas were detected and possible order families evacuation decrees were individuated. Moreover, thanks to the high detail of the DTM unstable blocks on difficult as vertical portion of the slope were identified and removed by the climbers. After the emergency phase was concluded, there was the necessity to put some protective barrier on the slope. To this aim, a set of simulated trajectory on DTM with the barrier was produced. So, in a first step an incremental Delaunay triangulation was performed on DTM model to produce a 3-dimensional simulations of the possible paths of the rockfall (Figure 3). 


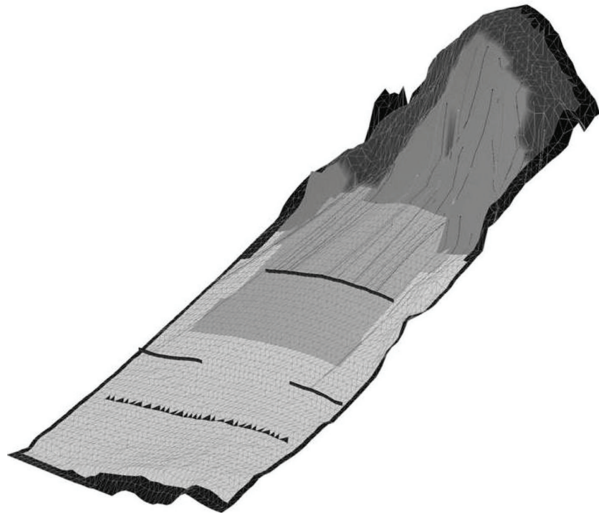

Figure 3: 3D simulations of the possible paths of the rockfall.

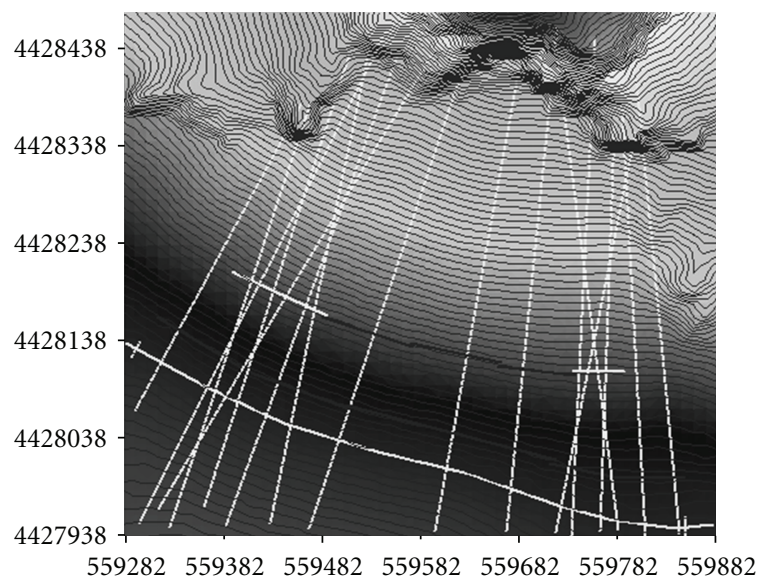

FIgURe 4: Location of the simulation profiles. Sections and SS18 road are indicated on the map. The area inside the rectangle represents the instable part of the slope.

The 3D project setting is characterized by 100 number of rock blocks with a volume of $2 \pm 1 \mathrm{~m}^{3}$, mass of $2.400 \mathrm{~kg} / \mathrm{m}^{3}$.

In a second step, to have more information on the single path, some 2-dimensional simulations of the trajectory of the rockfall, along some well-established profiles were performed.

The rockfall event has interested an area of $40.000 \mathrm{~m}^{2}$ located in the upper part of the slope. So, along the slope, 16 profiles have been located to effectuated 2D simulations (Figure 4).

The 2D project setting is characterised by 500 number of rocks with a volume of $2 \pm 1 \mathrm{~m}^{3}$ and a mass of $2.400 \mathrm{~kg} / \mathrm{m}^{3}$, normal and tangential coefficients are the same reported on Table 1. The results of the simulations (Figure 5) were used to design dynamic barriers (Figure 6).

Within two months 260 linear meters of high-energy rockfall barriers for impact energies up to $3000 \mathrm{~kJ}$ and $h=$ $5.00 \mathrm{~m}$ were installed. After that, according to ANAS road authority, the SS18 road was opened in a safe condition.

\section{Conclusions}

A new approach has been applied for investigating rockfall landslides in Basilicata Region. In particular an airborne

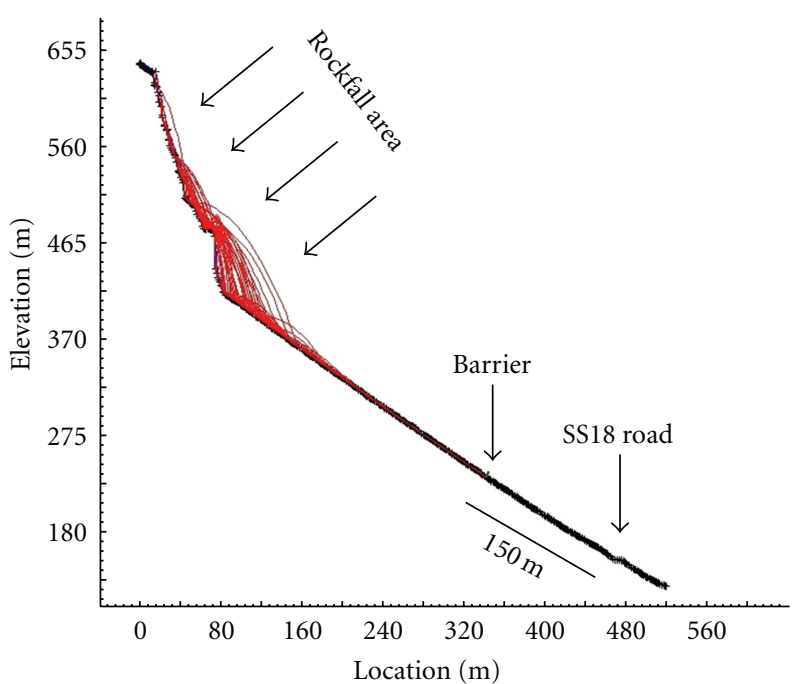

FIGURE 5: Example of the various rockfall layouts for profile n.10 with trajectory and protective barrier.

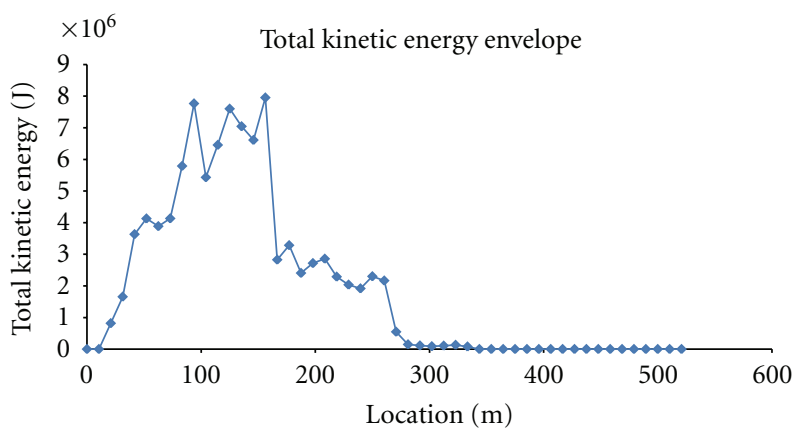

(a)

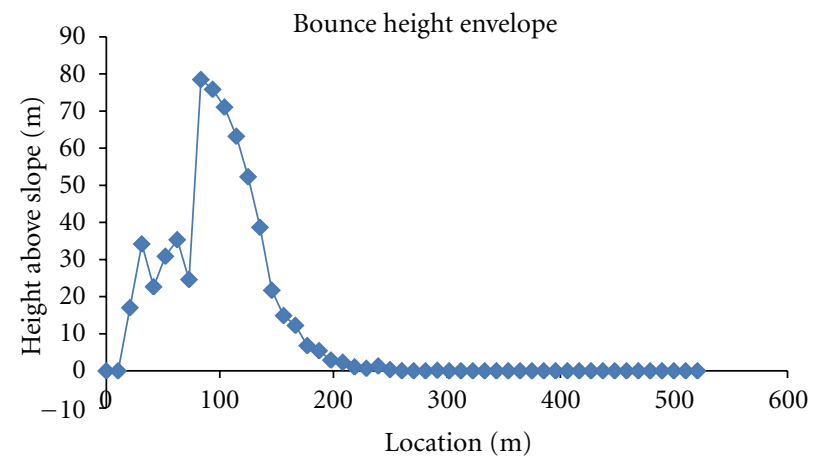

(b)

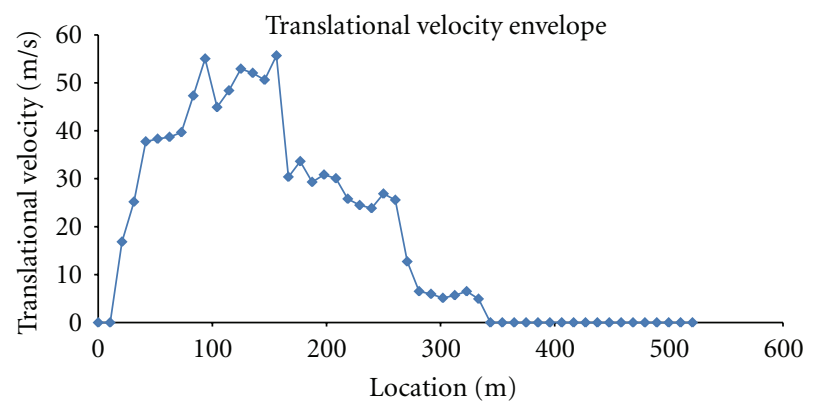

(c)

FIgURE 6: Example of analysis along the profile n.10. 
LiDAR technique has been used to study the morphology of the area through a high-resolution DTM.

The main objectives of RDICP were the safety of the peoples and the way to follow the evolution of the event with simulation models.

Geological, geomorphological, and impact sighs along the slope have been used for the back analysis.

Subsequently, a high-resolution DEM has been used to obtain simulation about the trajectory of the landslide blocks.

The simulations allowed us to design the protective barriers for the mitigation of the phenomena. The information obtained by the application of indirect surveys appeared to be particularly useful for the endusers involved in the risks management. In particular, taking into account the frequency of landslide events, the obtained data could give a valid contribution regarding the damage valuation and the intervention actions.

The DTM associated with the simulations had a dual use, both during the emergency and in the phase of design engineering solution.

This approach, fast and economic, gives us an interpretative tool to evaluate possibly evacuation decrees through the simulations of the trajectories and a second time to design the intervention actions for the mitigation of the phenomena.

\section{Acknowledgments}

Thanks to V. Mancusi, A. Lanotte, L. Laurino, and V. Cavallo for the technical support during the field emergency management, GeoAmbiente s.r.l. for the availability during the different phases of the work, and A. Vicari for the useful suggestions on the paper.

\section{References}

[1] O. Stuart, "20th-Century urban landslides in the basilicata region of Italy," Environmental Management, vol. 17, no. 4, pp. 433-444, 1993.

[2] M.-H. Derron and M. Jaboyedoff, "LIDAR and DEM techniques for landslides monitoring and characterization," Natural Hazards and Earth System Science, vol. 10, no. 9, pp. 18771879, 2010.

[3] W. H. Schulz, "Landslide susceptibility revealed by LIDAR imagery and historical records, Seattle, Washington," Engineering Geology, vol. 89, no. 1-2, pp. 67-87, 2007.

[4] L. R. Alejano, B. Pons, F. G. Bastante, E. Alonso, and H. W. Stockhausen, "Slope geometry design as a means for controlling rockfalls in quarries," International Journal of Rock Mechanics and Mining Sciences, vol. 44, no. 6, pp. 903-921, 2007.

[5] D. Scrocca, E. Carminati, and C. Doglioni, "Deep structure of the southern Apennines, Italy: thin-skinned or thickskinned?" Tectonics, vol. 24, no. 3, pp. 1-20, 2005.

[6] M. Polemio and G. D’Ecclesiis, "Aquifer vulnerability in Maratea Mountains (southern Italy)," Geografia Fisica e Dinamica Quaternaria, vol. 20, no. 1, pp. 113-117, 1997.

[7] C. Mallardo, "Frane da crollo nel territorio comunale di Maratea (PZ)," Geologia Territorio e Ambiente, vol. 2, pp. 3-6, 2002.
[8] G. Spilotro, A. Petraglia, and V. Pizzo, "Relazione generale strada statale N18 'tirrena inferiore'” Assistenza Tecnica per l' acquisizione ed il trattamento dei dati necessari alla zonazione della pericolosità e del rischio di caduta massi lungo il tratto di strada compreso tra $i \mathrm{~km} \mathrm{220+600} \mathrm{e} \mathrm{243+670.ANAS,}$ Compartimento Regionale della Viabilità, Potenza, 2009.

[9] GeoRock3D 2009. Geostru, Ver.1.rev.70.

[10] Rocscience, Rocfall, Statistical Analysis of Rockfalls. Ver. 4.042, 2004. 

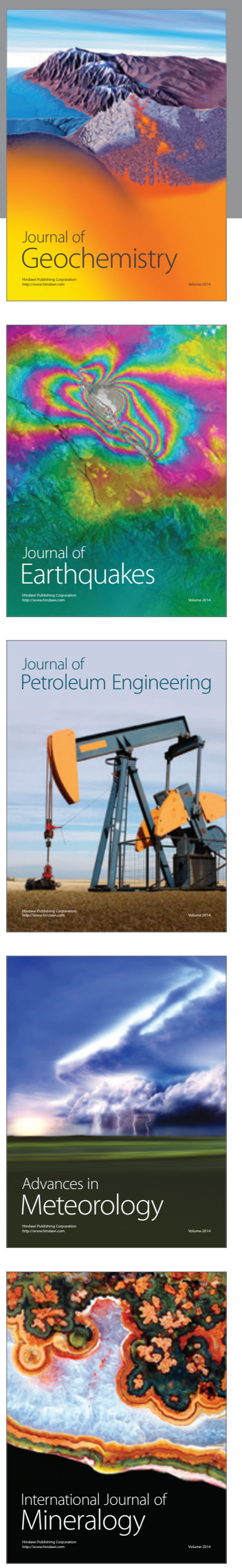
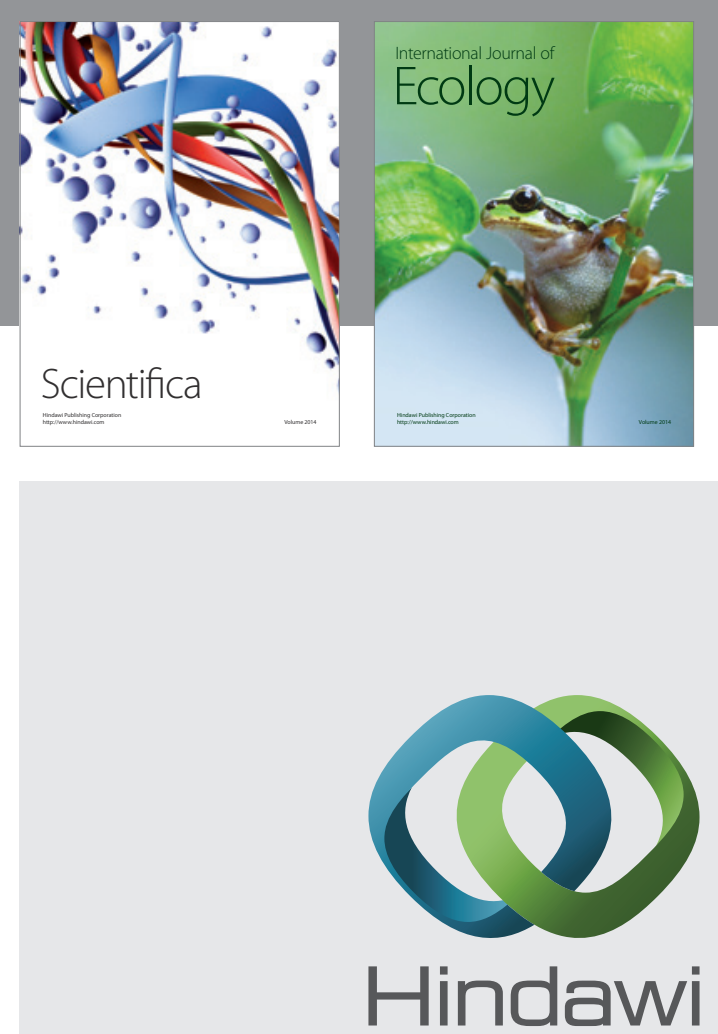

Submit your manuscripts at http://www.hindawi.com

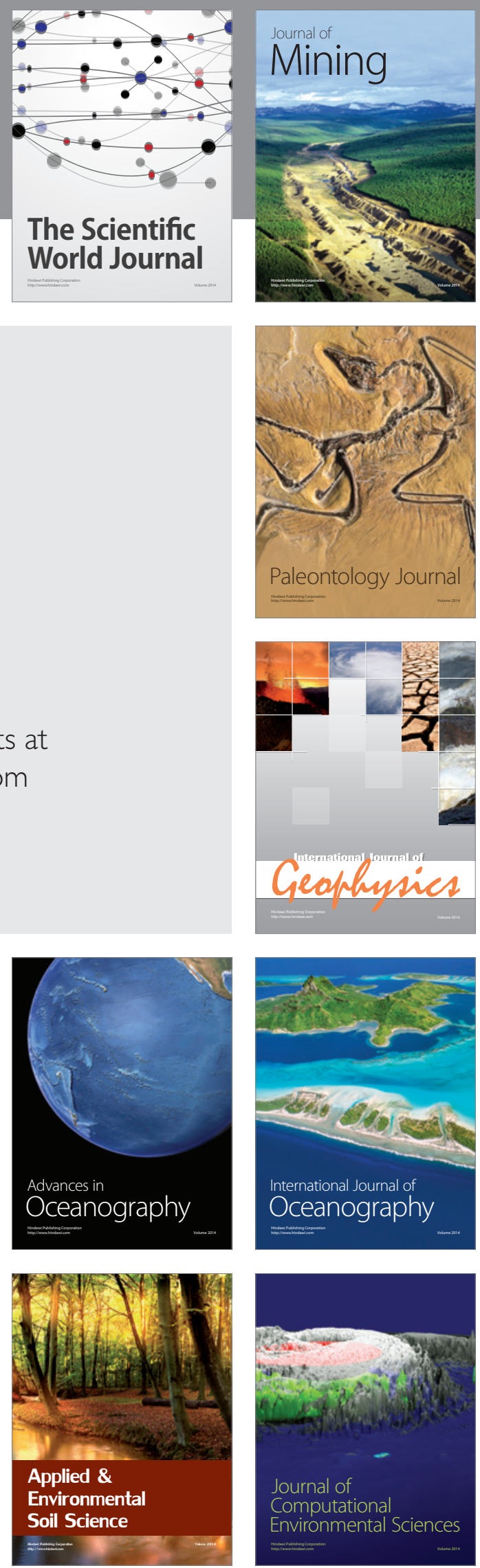